\title{
Resilience of Canadian homes and small buildings to the effects of climate change - Risk of deterioration due to condensation within wall assemblies
}

\author{
Maurice Defo ${ }^{1, *}$, and Michael Lacasse ${ }^{1}$ \\ ${ }^{1}$ National Research Council, Construction Research Centre, 1200 Montreal Road, Ottawa, Canada
}

\begin{abstract}
The objective of this study was to assess the potential effects of climate change on the moisture performance and durability of typical Canadian wood-frame walls using hygrothermal simulations, with a particular attention to the risk of condensation. To reduce the risk of condensation, the National Building Code of Canada (NBCC) recommends a maximum air leakage rate of $0.10 \mathrm{~L} / \mathrm{sm}^{2}$ at $75 \mathrm{~Pa}$ in buildings with interior relative humidity not greater than $55 \%$. This leakage rate was evaluated in five cities across Canada for a wood-frame wall having brick cladding, with and without outdoor insulation and both walls meeting the minimum insulation requirements given in NBCC. It is found that the risk of condensation will be reduced in the future in all 5 cities analysed. The reduction in the risk of condensation is slightly higher for the wall with no exterior insulation than for the wall with exterior insulation. This reduction in the risk of condensation means that the limit of $0.10 \mathrm{~L} /\left(\mathrm{sm}^{2}\right)$ for building having a warm side relative humidity of less than $55 \%$ may be reconsidered in the future. There may however be some risks associated with the increase in rain in some cities.
\end{abstract}

\section{Introduction}

In cold climates, air leakage through the wall assembly, especially air exfiltration during the heating season, decreases the energy efficiency of the building [1], but significantly, can also lead to condensation within the wall that may cause premature deterioration of building envelope components [2]. The majority of moisture problems resulting from condensation of water vapour in walls, ceiling and attic spaces are caused by the leakage of warm moist interior air into these spaces rather than by the diffusion of water vapour through the building envelope [3].

To minimize moisture problems associated with air leakage, the National Building Code of Canada (NBCC) [3] states that air leakage must be controlled to a level where the occurrence of condensation will be sufficiently rare, or the quantities accumulated sufficiently small, and drying sufficiently rapid to avoid material deterioration and the growth of mould and fungi. This can be achieved by using an air barrier system in opaque insulated portions of the building with an air leakage rate not greater than $0.15,0.10$, and $0.05 \mathrm{~L} /\left(\mathrm{s} . \mathrm{m}^{2}\right)$ at a reference pressure of 75 $\mathrm{Pa}$ when the warm side relative humidity $(\mathrm{RH})$ is less than $27 \%$, between 27 to $55 \%$, and greater than $55 \%$, relatively [3]. However, such provisions were set without consideration of the projected effects of climate loads acting on buildings as may arise in the future from a warming climate. Global warming now in effect with more frequent and intense extreme climate events [4], there is a need to assess the resilience of wall assemblies to the risk of the formation of condensation, moisture uptake and the possible presence of mould growth in components or decay fungi in wood.

The objective of this study was therefore to assess the potential effects of climate change on the moisture performance and durability of typical Canadian woodframe walls using hygrothermal simulations, with a particular attention to the risk of condensation. For this preliminary study, only the leakage rate of $0.10 \mathrm{~L} /\left(\mathrm{sm}^{2}\right)$ at $75 \mathrm{~Pa}$ is evaluated, the maximum recommended for buildings where the maximum indoor relative humidity is not greater than $55 \%$. The hypothesis is that the global warming may reduce the risk of condensation within wall, in which case the current performance requirements will be met in the future. The evaluation follows the procedure described [5].

\section{Methods}

\subsection{Cities selected}

For this study, five cities were selected for the analysis: Vancouver (British Columbia), Calgary (Alberta), Ottawa (Ontario), St. Johns (Newfoundland and Labrador), and Winnipeg (Manitoba). Their geographical locations and current climate design data as reported in the 2015 edition of the National Building Code of Canada [3] and are given in Table 1. These cities cover a wide range of HeatingDegree days (HDD) and moisture index (MI). The driving

* Corresponding author: maurice.defo@nrc-cnrc.gc.ca 
Rain Wind pressure (DRWP) is $400 \mathrm{~Pa}$ in St. John's (NL), almost the double of the DRWP in other four cities.

Table 1. Geographical location and current climate design data of the selected cities.

\begin{tabular}{|c|c|c|c|c|c|c|c|c|}
\hline City (Province) & $\begin{array}{l}\text { Lat } \\
\left(^{\circ}\right) \\
\end{array}$ & $\begin{array}{c}\text { Long } \\
\left(^{0}\right)\end{array}$ & $\mathrm{TZO}$ & $\mathrm{CZ}$ & HDD & MI & $\begin{array}{l}\text { Rain } \\
(\mathrm{mm})\end{array}$ & $\begin{array}{c}\text { DRWP } \\
(\mathrm{Pa})\end{array}$ \\
\hline Vancouver $(\mathrm{BC})^{1}$ & 49.3 & -123 & -8 & 4 & 2825 & 1.44 & 1400 & 160 \\
\hline Ottawa $(\mathrm{ON})^{2}$ & 45.3 & -75.4 & -5 & 6 & 4500 & 0.84 & 750 & 160 \\
\hline St. John's (NL) & 47.6 & -52.7 & -4 & 6 & 4800 & 1.41 & 1200 & 400 \\
\hline Calgary (AB) & 51.1 & -114 & -7 & $7 \mathrm{~A}$ & 5000 & 0.37 & 325 & 220 \\
\hline Winnipeg (MB) & 49.9 & -97.1 & -6 & $7 \mathrm{~A}$ & 5670 & 0.58 & 415 & 180 \\
\hline
\end{tabular}

\subsection{Building and wall assemblies}

A 3.5-storey residential building (10-m height) with sloped roof located in a suburban area was considered for the analysis, such a building being compliant with NBCC Part 9, homes and small buildings. Two 2x6 (38 x 140 $\mathrm{mm})$ wood-framed walls were analysed: a reference wall with stud cavity insulation (W1), and an energy-retrofitted wall with outboard insulation (W2). The configuration of the two walls is shown in Table 2 and Fig. 1. The glass fibre batt selected for stud cavity insulation has a thermal resistance, RSI, of $3.34 \mathrm{~m}^{2} \mathrm{~K} / \mathrm{W}$. With a stud spacing of $600 \mathrm{~mm}$, the effective RSI for wall W1 is $3.03 \mathrm{~m}^{2} \mathrm{~K} / \mathrm{W}$, which meets the minimum energy requirement for an above-grade opaque wall in each of the climate zones considered when home is equipped with an heat recovery system, i.e., 2.78 for climate Zone 4, and 2.97 for Zones 5, 6 and 7A [3]. As well, the 25-mm EPS used as outboard insulation in wall $\mathrm{W} 2$ has a RSI value of $0.71 \mathrm{~m}^{2} \mathrm{~K} / \mathrm{W}$, which gives a RSI ratio of outboard to inboard insulation of 0.41 . This value is above the minimum RSI ratio of 0.2 and 0.3 recommended for Zones 4 and 6 , and 7A, respectively, to minimize the risk of condensation on the plane of lower permeance [3].

Only the wall assembly of the third floor of the home, and where the air exfiltration due to the stack effect is the highest during the heating season, was considered. This position represents the worst case scenario in terms of the risk of condensation in cold climates.

Table 2. Wall components and materials

\begin{tabular}{|c|c|c|c|c|}
\hline Wall component & Material & $\begin{array}{c}\text { Thickness } \\
\text { (mm) }\end{array}$ & W1 & W2 \\
\hline Cladding & Brick veneer & 90.0 & $\mathrm{x}$ & $\mathrm{X}$ \\
\hline Drianage cavity & Air & 25.0 & $\mathrm{x}$ & $\mathrm{x}$ \\
\hline Outboard insulation & EPS & 25.4 & & $\mathrm{x}$ \\
\hline Sheathing membrane & SBP & 0.15 & $\mathrm{x}$ & $\mathrm{X}$ \\
\hline Exterior sheathing board & OSB & 11.0 & $\mathrm{x}$ & $\mathrm{x}$ \\
\hline Wood stud & Spruce & 140.0 & $\mathrm{x}$ & $\mathrm{x}$ \\
\hline Plate (top and bottom) & Spruce & 140.0 & $\mathrm{x}$ & $\mathrm{x}$ \\
\hline Stud cavity insulation & Glass fibre batt & 140.0 & $\mathrm{x}$ & $\mathrm{x}$ \\
\hline Vapour barrier & Polyethylene & 0.15 & $\mathrm{x}$ & $\mathrm{X}$ \\
\hline Interior sheathing board & Gypsum & 12.7 & $\mathrm{x}$ & $\mathrm{x}$ \\
\hline
\end{tabular}

EPS: Expanded polystyrene (EPS); SBP: Spun-bonded polyolefin

OSB: Oriented Strand board; $x$ : component is part of the wall assembly

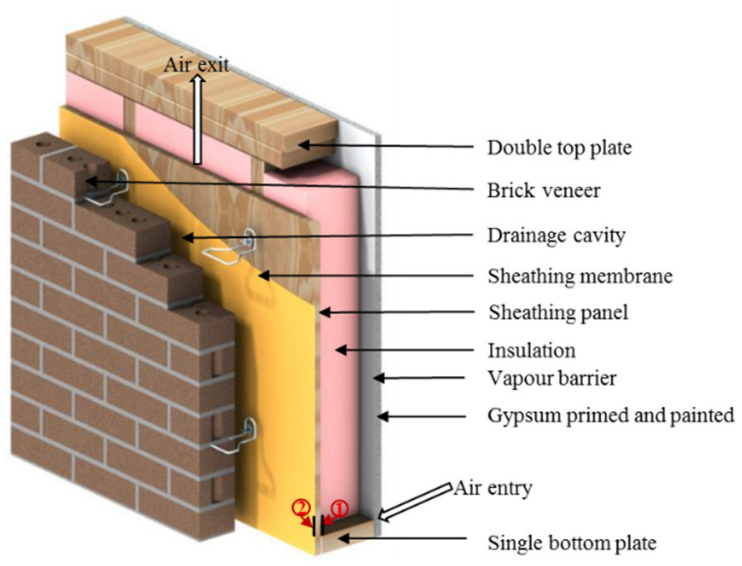

Fig. 1. Schematic of the wall with no outboard insulation (W1) showing the composition of the wall, the points of entry and exit of the air, and the critical points 1 and 2 where moisture performance is assessed.

Air flow through the imperfections in the air barrier system was calculated assuming an air leakage rate of 0.1 $\mathrm{L} /\left(\mathrm{s} . \mathrm{m}^{2}\right)$ at a pressure differential of $75 \mathrm{~Pa}$, the maximum value allowed for an above-grade opaque wall of residential buildings with an indoor $\mathrm{RH}<55 \%$ to minimize the risk of condensation [3]. Only the exfiltration of air was considered, i.e., no air infiltration. To implement the air leakage, it was assumed that: (i) with the exception of glass fibre used in the stud cavity, all other materials are air tight; (ii) air enters in the stud cavity through a single orifice located at the bottom of the interior wall (Fig. 1), diffuses through the insulation and finds its way out at the top of the wall between the top plate and the OSB (Fig. 1), which means there is no gap between the insulation and the adjacent layers. The air path selected is one of the paths that leads to a greater risk of condensation as suggested by Ojanen and Kumaran [2].

The equivalent leakage area (A) was estimated using Eq. 1 retrieved from ASHRAE [6] :

$$
A=\frac{Q_{r}\left(\frac{\rho}{2 \Delta P_{r}}\right)^{0.5}}{C_{D}}
$$

where,

A: equivalent leakage area $\left(\mathrm{m}^{2}\right)$

$\mathrm{Q}_{\mathrm{r}}$ : flow rate at reference pressure $\left(\mathrm{m}^{3} / \mathrm{s}\right)$

$\Delta \mathrm{P}_{\mathrm{r}}$ : reference pressure difference $(75 \mathrm{~Pa})$

$\rho:$ air density $\left(1.2 \mathrm{~kg} / \mathrm{m}^{3}\right)$

$\mathrm{C}_{\mathrm{D}}$ : Discharge coefficient

The discharge coefficient, $\mathrm{C}_{\mathrm{D}}$, was set to 0.6 , the value for a sharp-edged orifice [6]. The effective leakage area obtained at the reference pressure of $75 \mathrm{~Pa}(0.15$ $\mathrm{cm}^{2} / \mathrm{m}^{2}$ wall) was converted to the effective area at pressure of $10 \mathrm{~Pa}$, which is roughly the maximum pressure differential during the heating season. Since the simulations were run in 2D, the diameter of an equivalent circle was set as the width of the opening at the air entry side. 


\subsection{Climate loads}

The climate datasets used in this study were retrieved from the large ensemble of climates simulated by the Canadian Regional Climate Model-version 4 (CanRCM4), each initialized under a different set of initial conditions in the CanESM2 global climate model. A detailed description of the procedure used to generate historical and projected future climate data can be found in [7]. The data is comprised of a hourly time-series of climate variables necessary to undertake hygrothermal simulations for a baseline time-period spanning 19862016 and future time-periods of 31-year when global warming of $2{ }^{\circ} \mathrm{C}$ and $3.5^{\circ} \mathrm{C}$ (with reference to the baseline time-period) are expected to be reached in the future. The climatic datasets were generated to capture the effects of the internal variability of the climate on future climate projections in 15 hourly realizations or runs.

In this study, only the 31-year (1986-2016) historical (H) and future (2062-2092) time-period corresponding to global warming of $3.5{ }^{\circ} \mathrm{C}(\mathrm{F})$ were considered. Among the 15 runs of each dataset, a single run was selected as the basis to analyze the impact of climate change, which implies that the uncertainties associated with the climate data were not addressed. The median run in the historical data set was selected using the moisture index (MI) as defined in [8]. The MI of each run was calculated as the average of the 31 yearly normalized MI values of the run. The normalization was performed using all the $31 \times 15$ yearly sums of wind-driven rain and drying potential.

The difference in some of the climate variables between the historical and future data sets for the five cities considered are given in Table 3. The statistics are only based on the values of the median run. It can be observed that: (i) the annual average temperature will increase significantly between the two timelines in all five cities; (ii) the relative humidity will not change significantly but due to increase temperature, vapour pressure will increase; (iii) the annual rainfalls will increase in Ottawa, Calgary, St. John's and Winnipeg but will decrease in Vancouver; and (iv) the average annual wind speed will remain unchanged but with more fluctuations in St. John's and Calgary. It should be noted that the trend observed for the annual rainfall in Vancouver is different than that observed when the data for all the 15 runs are used as reported in [7].

Table 3. Comparison of the historical (H: 1986-2016) and the future (F: 2062-2092) annual average temperature, relative humidity, vapour pressure and wind speed, and annual sum of rain.

\begin{tabular}{llrrrrrrrrrr}
\hline \multirow{2}{*}{ Variable } & & \multicolumn{2}{c}{ Vancouver } & \multicolumn{2}{c}{ Ottawa } & \multicolumn{2}{c}{ St. John's } & \multicolumn{2}{c}{ Calgary } & \multicolumn{2}{c}{ Winnipeg } \\
\multirow{2}{*}{ Temperature $\left({ }^{\circ} \mathrm{C}\right)$} & Statistic & \multicolumn{1}{c}{ H } & \multicolumn{1}{c}{ F } & \multicolumn{1}{c}{ H } & \multicolumn{1}{c}{ F } & \multicolumn{1}{c}{ H } & \multicolumn{1}{c}{ F } & \multicolumn{1}{c}{ H } & \multicolumn{1}{c}{ F } & H & F \\
& Average & 10.5 & 14.7 & 6.7 & 11.5 & 3.7 & 7.9 & 4.7 & 9.5 & 3.7 & 9.0 \\
\multirow{2}{*}{ Relative humidity $(\%)$} & Average & 0.8 & 1.1 & 1.0 & 0.8 & 1.0 & 0.8 & 1.0 & 1.2 & 1.1 & 1.1 \\
& SD & 1.1 & 62.6 & 71.3 & 73.1 & 82.7 & 83.4 & 62.3 & 63.8 & 71.9 & 72.4 \\
\multirow{2}{*}{ Rain $(\mathrm{mm})$} & Average & $\mathbf{1 2 4 3 . 4}$ & $\mathbf{1 1 9 2 . 5}$ & 744.5 & 832.7 & 1125.8 & 1232.6 & 345.7 & 461.1 & 407.8 & 439.1 \\
& SD & 217.1 & 165.8 & 129.6 & 157.1 & 150.2 & 163.5 & 104.2 & 131.8 & 116.7 & 120.5 \\
\multirow{2}{*}{ Wind speed $(\mathrm{m} / \mathrm{s})$} & Average & 2.8 & 2.6 & 3.5 & 3.4 & 5.6 & 5.5 & 3.9 & 3.8 & 4.2 & 4.0 \\
& SD & 0.1 & 0.1 & 0.1 & 0.1 & 0.2 & 0.2 & 0.2 & 0.2 & 0.2 & 0.2 \\
\hline
\end{tabular}

SD: Standard deviation

\subsection{Hygrothermal simulations}

Hygrothermal simulations were performed using DELPHIN (version 5.9.5). A 2D configuration of the wall consisting of the vertical section going through the insulation cavity was considered (Fig. 1). This configuration excludes the stud but includes the top and bottom plates. Some properties of the material used in different layers of the wall are presented in Table 4 . Those properties as well as the other required properties were obtained from the NRC's material database [9].

Since the primary focus of this study was to address the risk to condensation due to the effects of climate change, the moisture reference years (MRYs) were selected from the 31-year series of the run selected in each city as the two consecutive years with the lowest average temperature during the heating period (October to April). With the uncertainties on the initial conditions of the wall, the year with the median MI of the 31-year series was used to condition the wall. The moisture reference years selected in each case are given in Table 5 and Table 6. Some of the climate variables of the selected reference years are provided.

The orientation of the wall was selected in each city and each timeline as the one having the highest average negative pressure differentials for the two test years. They are shown in Table 5. 
Table 4. Basic properties of material used.

\begin{tabular}{lrrccc}
\hline Material & $\begin{array}{c}\boldsymbol{\rho}_{\mathbf{o}} \\
\left(\mathbf{k g} / \mathbf{m}^{\mathbf{3}}\right)\end{array}$ & $\begin{array}{c}\mathbf{c}_{\mathbf{o}} \\
(\mathbf{J} / \mathbf{k g K})\end{array}$ & $\begin{array}{c}\mathbf{k}_{\mathbf{o}} \\
(\mathbf{W} / \mathbf{m K})\end{array}$ & $\begin{array}{c}\boldsymbol{\delta}_{\mathbf{v}} \\
(\mathbf{s})\end{array}$ & $\begin{array}{c}\mathbf{k}_{\mathbf{a}} \\
(\mathbf{k g} / \mathbf{m s P a})\end{array}$ \\
\hline Brick veneer & 1900 & 800 & 0.500 & $1.77 \mathrm{E}-12$ & - \\
Air & 1.2 & 1214 & 0.151 & $1.97 \mathrm{E}-10$ & - \\
SBP & 464 & 1250 & 0.248 & $6.12 \mathrm{E}-13$ & - \\
OSB & 600 & 1880 & 0.094 & $5.38 \mathrm{E}-13$ & - \\
Glass fibre batt & 11.5 & 840 & 0.043 & $1.72 \mathrm{E}-10$ & $3.54 \mathrm{E}-09$ \\
EPS & 14.8 & 1470 & 0.038 & $3.96 \mathrm{E}-12$ & - \\
Spruce & 400 & 1880 & 0.088 & $3.13 \mathrm{E}-12$ & - \\
Polyethylene & 1256 & 840 & 0.159 & $1.50 \mathrm{E}-16$ & - \\
Gypsum & 700 & 870 & 0.160 & $5.07 \mathrm{E}-12$ & - \\
\hline
\end{tabular}

Table 5. Moisture reference years and wall orientation.

\begin{tabular}{lccccc}
\hline & & & & & Wall \\
City & Timeline & Run & year & Test years & $\begin{array}{c}\text { orientation } \\
\left({ }^{\mathbf{0}}\right)\end{array}$ \\
\hline \multirow{2}{*}{ Vancouver } & H & 8 & 1994 & $1995-1996$ & 247.5 \\
& F & 8 & 2069 & $2066-2067$ & 0.0 \\
\hline \multirow{2}{*}{ Ottawa } & H & 15 & 1997 & $1991-1992$ & 337.5 \\
& F & 15 & 2085 & $2064-2065$ & 337.5 \\
\hline \multirow{2}{*}{ St. John's } & H & 15 & 2005 & $1989-1990$ & 337.5 \\
& F & 15 & 2083 & $2064-2065$ & 337.5 \\
\hline \multirow{2}{*}{ Calgary } & H & 1 & 2007 & $1990-1991$ & 157.5 \\
& F & 1 & 2070 & $2063-2064$ & 112.5 \\
\hline \multirow{2}{*}{ Winnipeg } & H & 9 & 2010 & $2002-2003$ & 45.0 \\
& F & 9 & 2070 & $2062-2063$ & 45.0 \\
\hline
\end{tabular}

DELPHIN allows for explicit calculation of air flow through wall components. The air exchange coefficient method (Eq. 2) was used to set the boundary conditions for air flow, with the air exchange coefficient at the indoor and outdoor sides of the wall set to $2 \mathrm{~s} / \mathrm{m}$.

$$
j_{a}=\beta_{a}\left(P_{\text {surf }}-P_{\text {sur }}\right)
$$

where,

$\mathrm{j}_{\mathrm{a}}$ : mass of convective air flux $\left(\mathrm{kg} / \mathrm{m}^{2} \mathrm{~s}\right)$

$\beta_{\mathrm{a}}$ : is the air exchange coefficient $(\mathrm{s} / \mathrm{m})$

$\mathrm{P}_{\text {surf: }}$ is the air pressure in the boundary element $(\mathrm{Pa})$

$\mathrm{P}_{\text {sur: }}$ air pressure in the surrounding environment $(\mathrm{Pa})$

The initial conditions for relative humidity $(\mathrm{RH})$ and temperature $(\mathrm{T})$ for all components were set to $50 \%$ and $21^{\circ} \mathrm{C}$, respectively.

Indoor $\mathrm{T}$ and $\mathrm{RH}$ were kept constant at $21^{\circ} \mathrm{C}$ and $50 \%$, respectively, assuming that the building is equipped with air conditioning and dehumidification.

The outdoor and indoor pressures were calculated from the total differential pressure, the sum of the wind and stack pressure differences.

Referring to ISO Standard 6946 [10], the indoor convective heat transfer coefficient was set to $2.5 \mathrm{~W} / \mathrm{m}^{2} \mathrm{~K}$, and the outdoor convective heat transfer coefficient was calculated using Eq. 3:

Table 6. Average annual T, RH, wind speed and annual sum of wind driven rain for the selected reference years.

\begin{tabular}{|c|c|c|c|c|c|c|c|}
\hline Variable & Timeline & MRYs & Vancouver & Ottawa & St-Johns & Calgary & Winnipeg \\
\hline \multirow{6}{*}{$\begin{array}{l}\text { Temperature } \\
\left({ }^{\circ} \mathrm{C}\right)\end{array}$} & \multirow{3}{*}{ Historical } & Conditionning & 10.4 & 5.4 & 3.2 & 4.7 & 3.4 \\
\hline & & Test year 1 & 10.3 & 5.9 & 2.2 & 4.2 & 2.4 \\
\hline & & Test year 2 & 8.8 & 5.7 & 2.7 & 3.4 & 1.5 \\
\hline & \multirow{3}{*}{ Future } & Conditionning & 13.6 & 11.8 & 8.3 & 8.3 & 8.7 \\
\hline & & Test year 1 & 12.7 & 10.4 & 6.9 & 7.5 & 9.5 \\
\hline & & Test year 2 & 12.9 & 10.6 & 7.2 & 8.1 & 6.2 \\
\hline \multirow{6}{*}{$\begin{array}{l}\text { Relative humidity } \\
\text { (\%) }\end{array}$} & \multirow{3}{*}{ Historical } & Conditionning & 61.7 & 70.4 & 83.4 & 63.1 & 71.8 \\
\hline & & Test year 1 & 62.8 & 73.3 & 84.1 & 66.0 & 74.6 \\
\hline & & Test year 2 & 61.4 & 72.9 & 84.0 & 62.6 & 75.1 \\
\hline & \multirow{3}{*}{ Future } & Conditionning & 60.9 & 73.8 & 84.0 & 63.4 & 71.9 \\
\hline & & Test year 1 & 62.8 & 75.0 & 84.2 & 65.5 & 68.7 \\
\hline & & Test year 2 & 61.5 & 71.7 & 83.1 & 63.1 & 74.7 \\
\hline \multirow{8}{*}{$\begin{array}{l}\text { Wind driving rain } \\
\left(\mathrm{kg} / \mathrm{m}^{2}\right)\end{array}$} & \multirow{4}{*}{ Historical } & Conditionning & 144.9 & 101.6 & 76.7 & 62.1 & 94.1 \\
\hline & & Test year 1 & 105.3 & 68.9 & 132.8 & 27.7 & 214.7 \\
\hline & & Test year 2 & 83.2 & 119.4 & 65.1 & 23.2 & 169.1 \\
\hline & & Sum & 333.4 & 289.9 & 274.7 & 113.1 & 477.8 \\
\hline & \multirow{4}{*}{ Future } & Conditionning & 32.9 & 110.5 & 117.0 & 23.3 & 69.2 \\
\hline & & Test year 1 & 35.0 & 110.1 & 129.9 & 36.5 & 71.0 \\
\hline & & Test year 2 & 12.8 & 92.1 & 94.5 & 61.3 & 113.5 \\
\hline & & Sum & 80.6 & 312.7 & 341.4 & 121.0 & 253.7 \\
\hline \multirow{6}{*}{$\begin{array}{l}\text { Wind speed } \\
(\mathrm{m} / \mathrm{s})\end{array}$} & \multirow{3}{*}{ Historical } & Conditionning & 2.9 & 3.6 & 5.5 & 3.6 & 4.1 \\
\hline & & Test year 1 & 3.1 & 3.7 & 5.5 & 3.9 & 4.4 \\
\hline & & Test year 2 & 2.8 & 3.6 & 5.5 & 3.9 & 3.8 \\
\hline & \multirow{3}{*}{ Future } & Conditionning & 2.5 & 3.5 & 5.6 & 3.7 & 4.1 \\
\hline & & Test year 1 & 2.7 & 3.5 & 5.4 & 3.8 & 4.3 \\
\hline & & Test year 2 & 2.6 & 3.3 & 5.7 & 3.9 & 4.0 \\
\hline
\end{tabular}




$$
\alpha_{c e}=4+4 V
$$

where,

$$
\begin{aligned}
& \alpha_{\mathrm{ce}} \text { : outdoor convective heat transfer coefficient } \\
& \left(\mathrm{W} / \mathrm{m}^{2} \mathrm{~K}\right) \\
& \mathrm{V} \text { : wind speed }(\mathrm{m} / \mathrm{s})
\end{aligned}
$$

The indoor radiative heat transfer coefficient was set to $5.5 \mathrm{~W} / \mathrm{m}^{2} \mathrm{~K}$ [10] whereas the longwave exchange between the cladding surface and the environment was explicitly calculated assuming longwave emissivity of 0.9 for the surface and the surrounding ground, and with ground surface temperature equal to the air temperature. The ground surface albedo was set to 0.2 . The shortwave absorption coefficient of the cladding was set 0.6 , assuming a red-coloured surface.

The outdoor and indoor convective vapour transfer coefficients were calculated using the outdoor and indoor convective heat transfer coefficients, respectively, and the Lewis number [11].

WDR was calculated using the ASHRAE 160-2016 standard method [12]:

$$
R_{w d r}=F_{E} \cdot F_{D} \cdot F_{L} \cdot U_{10} \cdot \cos \theta \cdot R_{h}
$$

where,

$F_{E}$ : rain exposure factor

$F_{D}:$ rain deposition factor

$F_{L}$ : empirical constant $\left(=0.2 \mathrm{~kg} \cdot \mathrm{s} /\left(\mathrm{m}^{3} \cdot \mathrm{mm}\right)\right)$

$U_{10}$ : hourly mean wind velocity at $10 \mathrm{~m}$

$\theta$ : angle between the normal to the wall and the wind direction

$R_{h}$ : rain intensity on the horizontal surface $(\mathrm{mm} / \mathrm{h})$.

$F_{E}$ was set to 1.0 for a building of $10 \mathrm{~m}$ height sheltered by surrounding buildings, and $\mathrm{F}_{\mathrm{D}}$ was set to 0.5 corresponding to a wall below a low-slope roof. It should be noted that the orientation of the wall was not always the one receiving the highest amount of wind-driven rain in all cases. The building was assumed to be water tight, so no moisture source was added in the structure as a result of rain infiltration other than that may have resulted from air exfiltration.

\subsection{Moisture performance evaluation}

Preliminary results showed that, based on the assumed air path, the elements located at the bottom of the OSB in contact with the insulation consistently showed higher relative humidity than those located at the top of the bottom plate in contact with the OSB layer. Hence that location at the bottom of OSB was thus considered at risk of formation of condensation. As such, the moisture content $\mathrm{u}\left(\mathrm{kg}_{\text {water }} / \mathrm{kg}_{\text {dry material }}\right)$, in percent, of a small layer of $1 \mathrm{~mm} \times 10 \mathrm{~mm}$ was used to assess the impact of climate change on the risk of condensation (critical position 1). The outer layer of the OSB, which is affected by the outdoor climate loads, was also analysed (critical position 2).

\section{Results and discussion}

Fig. 2 shows the relative humidity and temperature profiles of the outer layer of OSB (critical positon 2) in the cities of Vancouver, St. John's and Winnipeg for the wall with no outdoor insulation (W1). At this position, it can be noted that: (i) there is no difference between the $\mathrm{RH}$ and $\mathrm{T}$ values for the cases with and without air leakage; (ii) $\mathrm{T}$ values in the future (2062-2092) are consistently higher than for the baseline period (19862016), which is in agreement with the general increase in temperature due to global warming (Table 3 and

Table 6); (iii) In Vancouver and Winnipeg, $\mathrm{RH}$ values are lower in the future as compared to the baseline period whereas for St. John's, it is the opposite.

The results obtained for moisture content $u$ at critical position 2 for the five cities investigated are summarized in Table 7 in terms of average moisture content, maximum moisture content, absolute and relative differences in moisture content for the baseline and the future periods. In all cities, the moisture content of the outer layer of OSB is higher in wall W1 (no outdoor insulation) than in the wall W2 (outdoor insulation) for both historical and future periods. This is in agreement with results observed in field tests for similar wall configurations [13]. The relative differences in moisture content between future and historical periods are summarized in Fig. 3 for the cases with and without air leakage. It can be observed that the average and maximum moisture contents in the outer layer of OSB for wall W1 and W2 will decrease in the future in the cities of Vancouver and Winnipeg for both the cases with and without air leakage. In Ottawa, St. John's and Calgary, the average and maximum MC for both types of walls will increase in the future for the cases with and without air leakage.

Table 6 shows the sum of annual wind driven rain values over the three MRYs for historical and future periods. In Vancouver and Winnipeg, the sums of wind-driven rain are for the baseline period 333.4 and $477.8 \mathrm{~kg} / \mathrm{m}^{2}$, respectively, and for the future period 80.6 and 253.7 $\mathrm{kg} / \mathrm{m}^{2}$, respectively. In Ottawa, St. John's and Calgary, the sums of annual wind-driven rain over the three MRYs are for the baseline period 289.9, 274.7 and $113.1 \mathrm{~kg} / \mathrm{m}^{2}$, respectively, and for the future period $312.7,341.4$, and $121.0 \mathrm{~kg} / \mathrm{m}^{2}$, respectively. These trends in the total sum of wind-driven rain (decrease in Vancouver and Winnipeg, and increase in Ottawa, St. John's and Calgary) may explained the trends observed for moisture contents of the outer layer of OSB.

It should be pointed out that the wind-driven rain was calculated using the orientation that leads to the highest rate of air exfiltration, which is not always the same as the orientation leading to the highest wind-driven rain load. As such, the results observed for the outer layer of OSB may not be the same as those that would have been observed for the worse orientation in terms of risk due to wind-driven rain. 
Fig. 4 shows the relative humidity and temperature profiles of the small layer of OSB $(1 \mathrm{~mm} \times 10 \mathrm{~mm})$ in contact with the stud insulation at the bottom side of the wall (critical position 1), for the cities of Vancouver, St. John's and Winnipeg for that wall with no outdoor insulation (W1), which is the one at higher risk of formation of condensation due to the absence of outdoor insulation. The results are shown only for the heating season of the two test years (from October to April). It can be noted that: (i) air leakage of $0.1 \mathrm{~L} /\left(\mathrm{sm}^{2}\right)$ has no effect on the $\mathrm{T}$ profiles, both for historical and future periods in the three cities; (ii) the temperature at that position is higher for the future period than for the historical period in the three cities; (iii) air leakage causes an increase in RH in the historical and future periods; (iv) in Vancouver and Winnipeg, there is a decreasing trend in relative humidity in the future for both cases with and without air leakage whereas the opposite is observed in St. John's.

Table 8 shows, for cases with and without air leakage, the average and maximum moisture contents, and the absolute differences between the values obtained for the future and historical periods in all the cities at critical position 1 . The response varies with the type of wall and whether or not air leakage is considered. For the case with no air leakage, the results are similar to those obtained for the outer layer of OSB for wall W1, i.e., the risk of moisture accumulation in wall $\mathrm{W} 1$ decreases in the future in Vancouver and Winnipeg, and increases in Ottawa, St. John's and Calgary. For wall W2, moisture increases in the future as for wall W1 in Ottawa, St. John's, Calgary and Winnipeg. In Vancouver for wall W2 the average moisture content increases for the future as for wall W1, but the maximum remains the same. For the case with air leakage, the MC at critical position 1 will decrease on average in Vancouver, Ottawa, Calgary and Winnipeg for walls W1 and W2 whereas in St. John's, the MC will increase on average for both walls. These results are those observed at critical position 1 for the case of air exfiltration as expressed by the moisture response for the selected orientation that encompasses both the effects of outdoor moisture loads and air leakage.

a) Vancouver
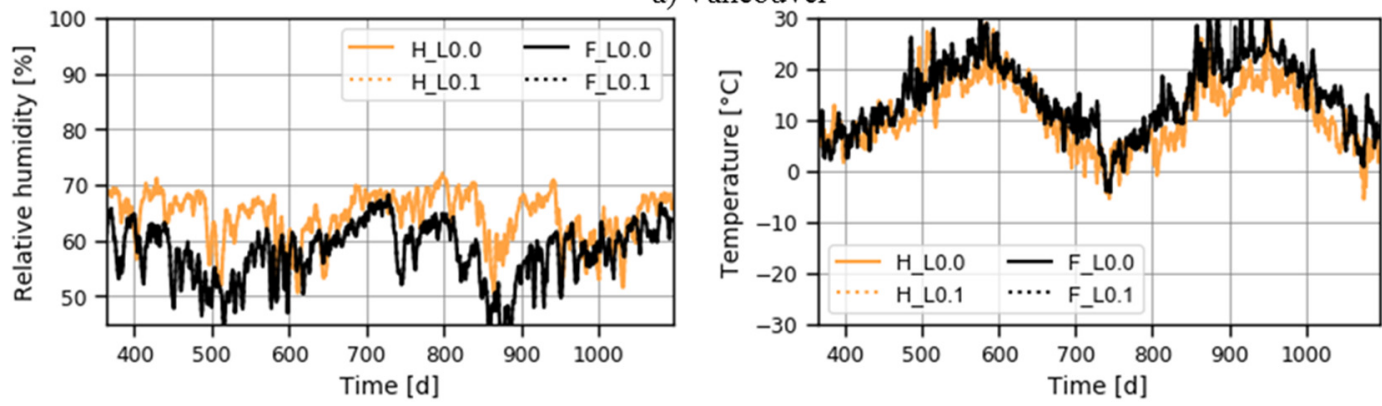

a) St. John's
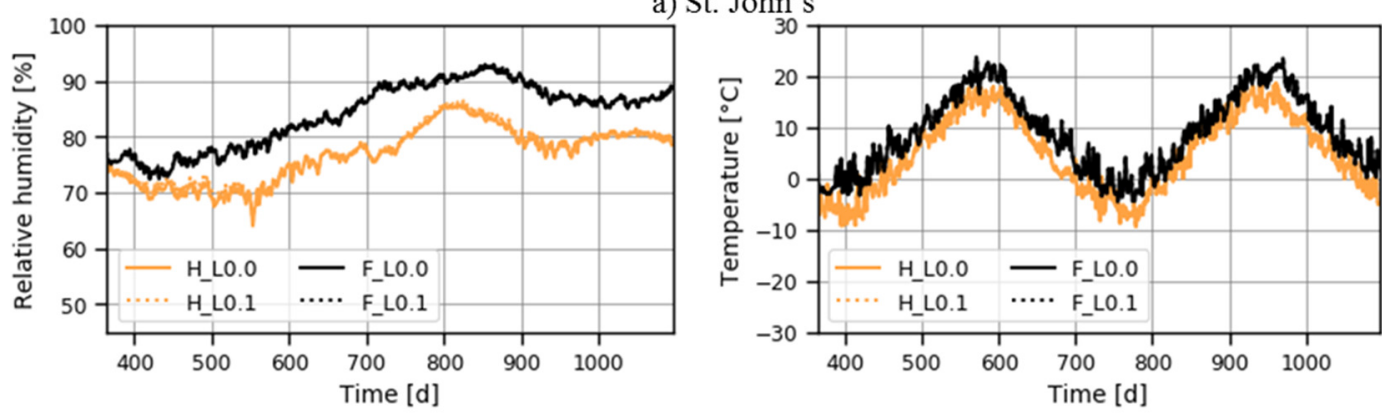

a) Winnipeg
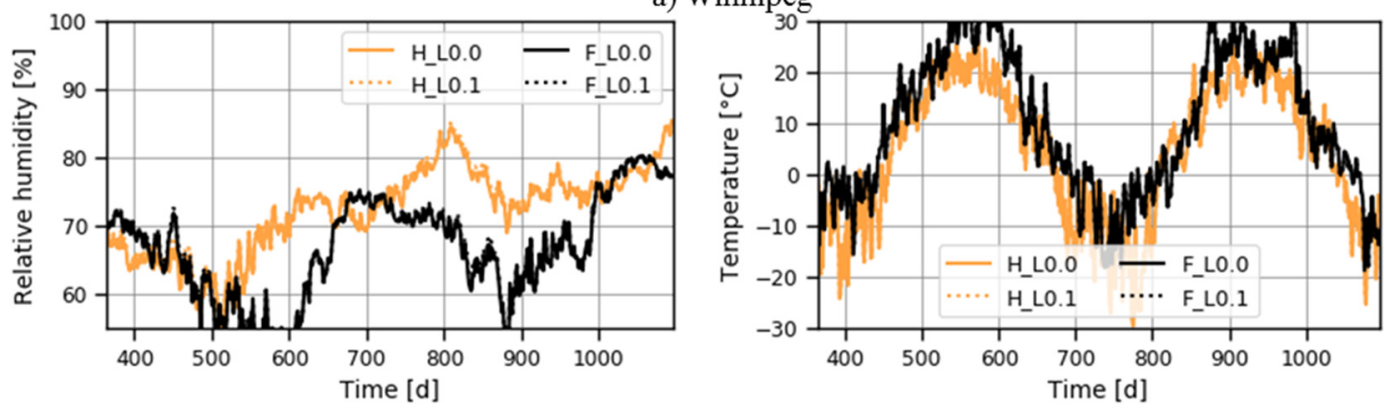

Fig. 2. Relative humidity and temperature profiles of the outer layer of OSB (critical position 2) in the wall with no outboard insulation (W1) for historical (H) and future (F) and for the case with no air leakage (L0.0) and with air leakage (L0.1). Results are only shown for the last two years. 
Table 7. Summary of results obtained for the moisture content $u(\%)$ in the outer layer of OSB (critical position 2).

\begin{tabular}{|c|c|c|c|c|c|c|c|c|c|c|}
\hline \multirow[b]{2}{*}{ City } & \multirow[b]{2}{*}{ Wall } & \multirow[b]{2}{*}{ Statistic } & \multicolumn{4}{|c|}{ Case with no leakage } & \multicolumn{4}{|c|}{ Case with leakage of 0.1} \\
\hline & & & $\mathbf{H}$ & $\mathbf{F}$ & $\Delta \mathbf{u}$ & $\Delta \mathbf{u}(\%)$ & $\mathbf{H}$ & $\mathbf{F}$ & $\Delta \mathbf{u}$ & $\Delta \mathbf{u}(\%)$ \\
\hline \multirow{4}{*}{ Vancouver } & \multirow{2}{*}{ W1 } & Average & 8.2 & 7.5 & -0.8 & -9.5 & 8.3 & 7.5 & -0.8 & -9.7 \\
\hline & & Maximum & 9.5 & 8.9 & -0.6 & -6.5 & 9.6 & 8.9 & -0.7 & -7.1 \\
\hline & \multirow{2}{*}{$\mathrm{W} 2$} & Average & 7.6 & 7.2 & -0.4 & -5.7 & 7.7 & 7.2 & -0.5 & -6.0 \\
\hline & & Maximum & 8.3 & 7.8 & -0.5 & -5.8 & 8.3 & 7.8 & -0.5 & -5.6 \\
\hline \multirow{4}{*}{ Ottawa } & \multirow{2}{*}{ W1 } & Average & 8.9 & 9.1 & 0.2 & 2.0 & 8.9 & 9.1 & 0.1 & 1.5 \\
\hline & & Maximum & 11.3 & 11.4 & 0.2 & 1.6 & 11.3 & 11.4 & 0.1 & 1.2 \\
\hline & \multirow{2}{*}{ W2 } & Average & 8.1 & 8.6 & 0.4 & 5.4 & 8.2 & 8.6 & 0.4 & 4.2 \\
\hline & & Maximum & 9.3 & 9.8 & 0.5 & 4.9 & 9.4 & 9.7 & 0.4 & 4.0 \\
\hline \multirow{4}{*}{ St. John's } & \multirow{2}{*}{ W1 } & Average & 10.7 & 13.1 & 2.5 & 23.0 & 10.8 & 13.2 & 2.4 & 22.0 \\
\hline & & Maximum & 13.9 & 19.1 & 5.2 & 37.3 & 14.3 & 19.4 & 5.1 & 35.5 \\
\hline & \multirow{2}{*}{ W2 } & Average & 8.6 & 10.2 & 1.7 & 19.5 & 8.8 & 10.4 & 1.6 & 18.0 \\
\hline & & Maximum & 9.7 & 12.4 & 2.7 & 28.4 & 9.8 & 12.5 & 2.7 & 27.2 \\
\hline \multirow{4}{*}{ Calgary } & \multirow{2}{*}{ W1 } & Average & 7.3 & 7.4 & 0.2 & 2.3 & 7.3 & 7.5 & 0.1 & 1.9 \\
\hline & & Maximum & 8.3 & 8.4 & 0.0 & 0.2 & 8.4 & 8.4 & 0.0 & 0.3 \\
\hline & \multirow{2}{*}{ W2 } & Average & 6.8 & 7.0 & 0.2 & 3.5 & 6.9 & 7.1 & 0.2 & 2.6 \\
\hline & & Maximum & 7.5 & 7.6 & 0.1 & 2.0 & 7.6 & 7.7 & 0.1 & 1.3 \\
\hline \multirow{4}{*}{ Winnipeg } & \multirow{2}{*}{ W1 } & Average & 9.6 & 8.6 & -1.0 & -10.1 & 9.7 & 8.6 & -1.0 & -10.6 \\
\hline & & Maximum & 13.7 & 11.6 & -2.1 & -15.4 & 13.8 & 11.6 & -2.2 & -15.7 \\
\hline & \multirow{2}{*}{ W2 } & Average & 8.2 & 7.9 & -0.3 & -3.8 & 8.4 & 8.0 & -0.4 & -4.9 \\
\hline & & Maximum & 9.9 & 9.4 & -0.5 & -4.7 & 9.9 & 9.4 & -0.6 & -5.7 \\
\hline
\end{tabular}

$\Delta \mathrm{u}$ : Difference in moisture content between future and historical periods

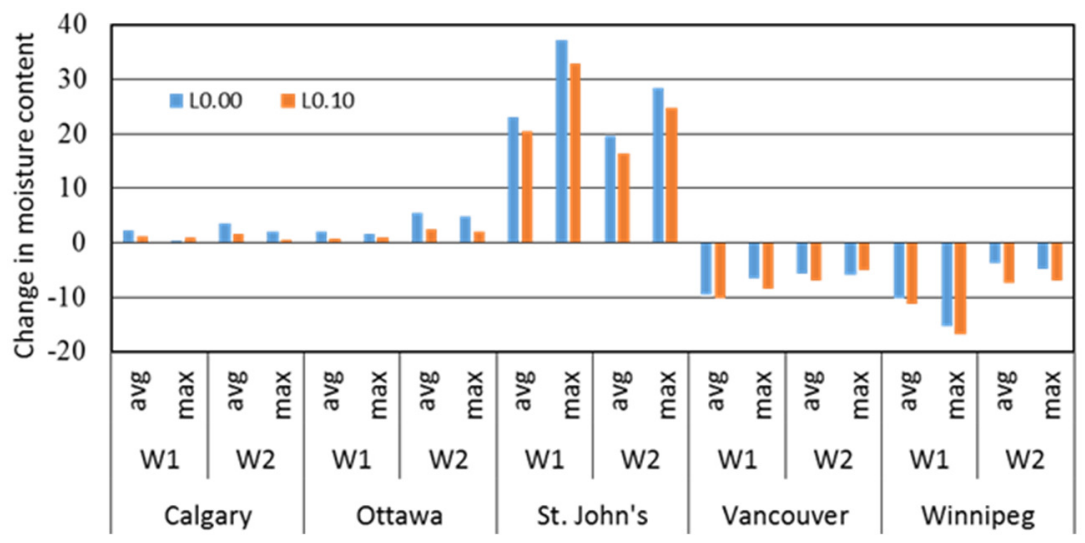

Figure 3. Relative change (\%) in average (avg) and maximum (max) moisture content u between future and historical periods at critical position 2 . 
a) Vancouver
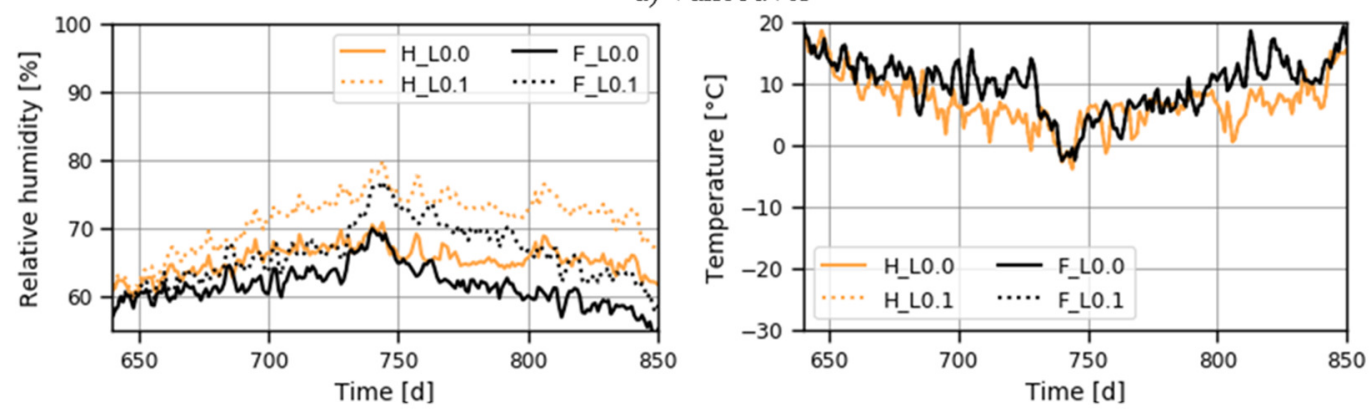

a) St. John's
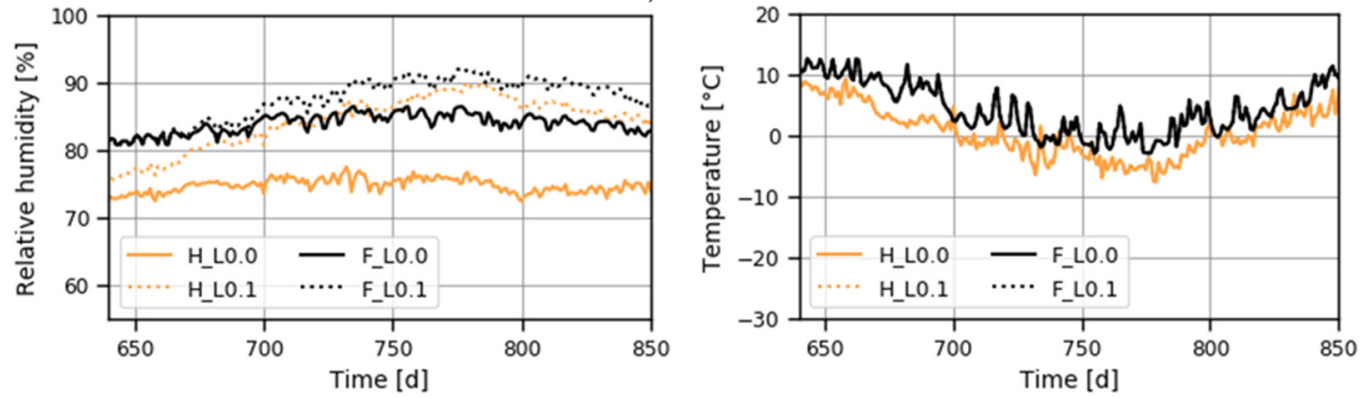

a) Winnipeg
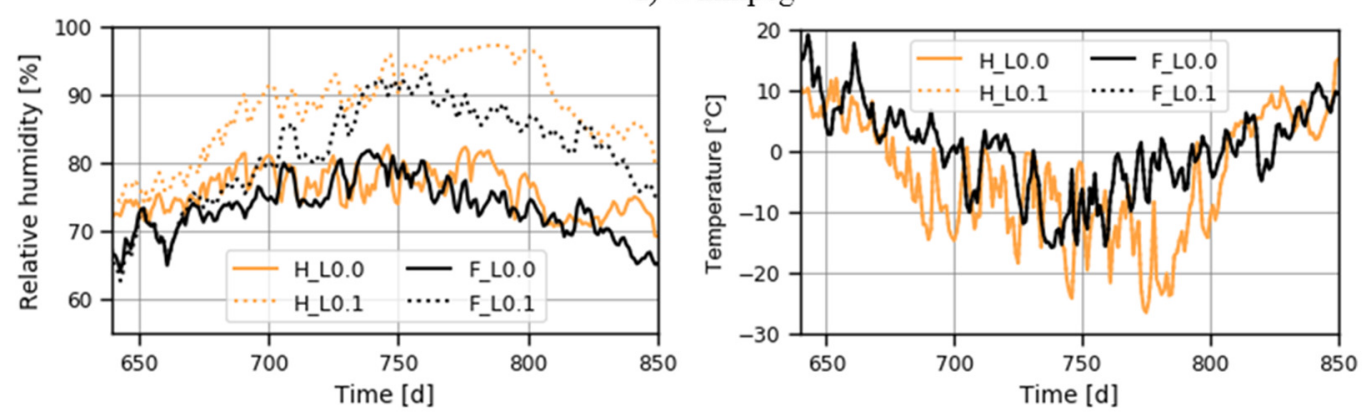

Fig. 4. Relative humidity and temperature profiles of OSB at critical position 1 in wall W1 (wall with no outer insulation) for historical (H) and future (F) and for the case with no air leakage (L0.0) and with air leakage (L0.1). Results are only shown for the heating season, from October to April.

To further the analysis, the difference in moisture content for the cases with and without air leakage $\left(\Delta \mathrm{u}_{\mathrm{F}}-\right.$ $\Delta \mathrm{u}_{\mathrm{H}}$ ) was calculated for historical and future periods in order to extract and compare the impact of climate change on the risk of formation of condensation due to air leakage only (Table 8 and Fig. 5). By doing so, it is assumed that there are no interactions between the indoor and outdoor moisture fluxes, which is, evidently, not strictly true. But this approach does provide some indication of the extent to which air leakage might be affected by climate change. For all the cities and for the two types of wall, the accumulation of moisture content due to air leakage alone will decrease. This general trend is in agreement with the higher outdoor $\mathrm{T}$ for the future timeline which maintains the OSB at a warmer $\mathrm{T}$ as compared to historical timeline (Fig. 4). This relative high temperature of the interior side of the OSB contributes to the reduction of water activity of the incoming indoor air in the stud cavity.

The decrease in moisture content at the critical position 1 is higher for wall W1 than for wall W2 (Table 8). Fig. 6 shows the T profiles during the heating season at that position for walls $\mathrm{W} 1$ and $\mathrm{W} 2$ for historical and future timelines for the case with no air leakage in the city of Winnipeg. The temperature at that position is warmer in wall W2 (with outdoor insulation) than in wall W1 (without outdoor insulation) for both historical and future periods. The difference between the future and historical average and maximum $\mathrm{T}$ values for walls W1 (wall with no outboard insulation) and W2 (wall with outboard insulation) are 4.9 and 7.4 , and 4.0 and $5.9^{\circ} \mathrm{C}$, respectively. These lower values for average and maximum $\mathrm{T}$ in $\mathrm{W} 2$ relative to $\mathrm{W} 1$ can explain the smaller effect of climate change in moisture accumulation in W2. 
Table 8. Summary of results obtained for the moisture content $\mathrm{u}(\%)$ at critical position 1 (small layer ( $1 \mathrm{~mm} \times 10 \mathrm{~mm}$ ) of OSB in contact with stud insulation at the bottom side).

\begin{tabular}{|c|c|c|c|c|c|c|c|c|c|c|c|c|c|c|c|}
\hline \multirow[b]{2}{*}{ City } & \multirow[b]{2}{*}{ Wall } & \multirow[b]{2}{*}{ Statistic } & \multicolumn{3}{|c|}{ Case with no leakage } & \multicolumn{3}{|c|}{ Case with leakage } & \multicolumn{3}{|c|}{ Historical } & \multicolumn{3}{|c|}{ Future } & \multirow[b]{2}{*}{$\Delta \mathbf{u}_{\mathrm{F}} \cdot \Delta \mathbf{u}_{\mathbf{H}}$} \\
\hline & & & $\mathbf{H}$ & $\mathbf{F}$ & $\Delta \mathbf{u}$ & $\mathbf{H}$ & $\mathbf{F}$ & $\Delta \mathbf{u}$ & LO.0 & L0.1 & $\overline{\Delta \mathbf{u}_{\mathrm{H}}}$ & LO.0 & LO.1 & $\Delta \mathbf{u}_{\mathrm{F}}$ & \\
\hline \multirow{4}{*}{ Vancouver } & \multirow{2}{*}{ W1 } & Average & 8.4 & 7.9 & -0.5 & 9.4 & 8.5 & -0.9 & 8.4 & 9.4 & 1.0 & 7.9 & 8.5 & 0.6 & -0.4 \\
\hline & & Maximum & 9.3 & 9.1 & -0.2 & 11.5 & 10.6 & -0.9 & 9.3 & 11.5 & 2.2 & 9.1 & 10.6 & 1.5 & -0.7 \\
\hline & \multirow{2}{*}{ W2 } & Average & 7.5 & 7.3 & -0.2 & 8.3 & 7.9 & -0.5 & 7.5 & 8.3 & 0.8 & 7.3 & 7.9 & 0.5 & -0.2 \\
\hline & & Maximum & 7.9 & 7.9 & 0.0 & 9.2 & 8.9 & -0.4 & 7.9 & 9.2 & 1.4 & 7.9 & 8.9 & 1.0 & -0.4 \\
\hline \multirow{4}{*}{ Ottawa } & \multirow{2}{*}{ W1 } & Average & 10.2 & 10.9 & 0.7 & 13.0 & 12.3 & -0.7 & 10.2 & 13.0 & 2.8 & 10.9 & 12.3 & 1.4 & -1.4 \\
\hline & & Maximum & 12.6 & 14.2 & 1.7 & 20.4 & 19.3 & -1.1 & 12.6 & 20.4 & 7.8 & 14.2 & 19.3 & 5.0 & -2.8 \\
\hline & \multirow{2}{*}{ W2 } & Average & 8.5 & 9.3 & 0.8 & 10.2 & 10.1 & -0.1 & 8.5 & 10.2 & 1.6 & 9.3 & 10.1 & 0.8 & -0.8 \\
\hline & & Maximum & 9.8 & 10.9 & 1.1 & 12.7 & 12.9 & 0.2 & 9.8 & 12.7 & 2.9 & 10.9 & 12.9 & 2.0 & -0.8 \\
\hline \multirow{4}{*}{ St. John's } & \multirow{2}{*}{ W1 } & Average & 10.1 & 13.1 & 3.0 & 13.2 & 15.0 & 1.8 & 10.1 & 13.2 & 3.1 & 13.1 & 15.0 & 1.9 & -1.2 \\
\hline & & Maximum & 10.8 & 14.3 & 3.5 & 16.5 & 18.4 & 1.8 & 10.8 & 16.5 & 5.7 & 14.3 & 18.4 & 4.0 & -1.7 \\
\hline & \multirow{2}{*}{ W2 } & Average & 8.0 & 9.8 & 1.8 & 9.9 & 10.9 & 1.0 & 8.0 & 9.9 & 1.8 & 9.8 & 10.9 & 1.1 & -0.8 \\
\hline & & Maximum & 8.4 & 10.4 & 2.0 & 10.9 & 11.9 & 1.0 & 8.4 & 10.9 & 2.5 & 10.4 & 11.9 & 1.5 & -1.0 \\
\hline \multirow{4}{*}{ Calgary } & \multirow{2}{*}{ W1 } & Average & 7.6 & 7.9 & 0.3 & 10.0 & 9.8 & -0.2 & 7.6 & 10.0 & 2.4 & 7.9 & 9.8 & 1.9 & -0.5 \\
\hline & & Maximum & 9.2 & 9.6 & 0.4 & 15.4 & 15.2 & -0.3 & 9.2 & 15.4 & 6.2 & 9.6 & 15.2 & 5.6 & -0.6 \\
\hline & \multirow{2}{*}{ W2 } & Average & 6.8 & 7.1 & 0.3 & 8.5 & 8.5 & -0.1 & 6.8 & 8.5 & 1.7 & 7.1 & 8.5 & 1.4 & -0.3 \\
\hline & & Maximum & 7.6 & 7.9 & 0.3 & 11.2 & 11.0 & -0.2 & 7.6 & 11.2 & 3.6 & 7.9 & 11.0 & 3.1 & -0.5 \\
\hline \multirow{4}{*}{ Winnipeg } & \multirow{2}{*}{ W1 } & Average & 10.4 & 9.8 & -0.6 & 15.3 & 12.2 & -3.1 & 10.4 & 15.3 & 4.9 & 9.8 & 12.2 & 2.3 & -2.5 \\
\hline & & Maximum & 12.5 & 12.2 & -0.3 & 26.4 & 19.5 & -6.9 & 12.5 & 26.4 & 13.8 & 12.2 & 19.5 & 7.2 & -6.6 \\
\hline & \multirow{2}{*}{ W2 } & Average & 8.3 & 8.4 & 0.1 & 11.0 & 9.7 & -1.2 & 8.3 & 11.0 & 2.7 & 8.4 & 9.7 & 1.3 & -1.3 \\
\hline & & Maximum & 9.2 & 9.4 & 0.2 & 16.1 & 12.2 & -3.9 & 9.2 & 16.1 & 6.8 & 9.4 & 12.2 & 2.8 & -4.1 \\
\hline
\end{tabular}

$\Delta \mathrm{u}$ is the difference between the future and historical moisture contents

$\Delta \mathrm{u}_{\mathrm{H}}$ is the difference between the cases with and without air leakage for historical period

$\Delta \mathrm{u}_{\mathrm{F}}$ is the difference between the cases with and without air leakage for historical period

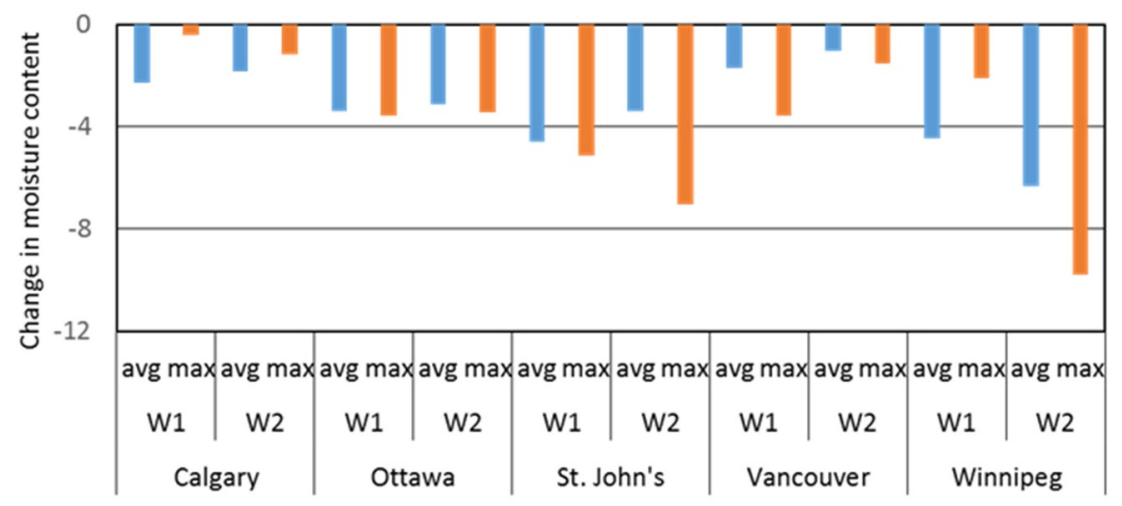

Fig. 5. Absolute difference $\left(\Delta \mathrm{uF}_{\mathrm{F}}-\Delta \mathrm{uH}_{\mathrm{H}}\right)$ between the difference in moisture content obtained with and without air leakage for future ( $\left.\Delta \mathrm{uF}_{\mathrm{F}}\right)$ and historical $\left(\Delta \mathrm{u}_{\mathrm{H}}\right)$ periods. 


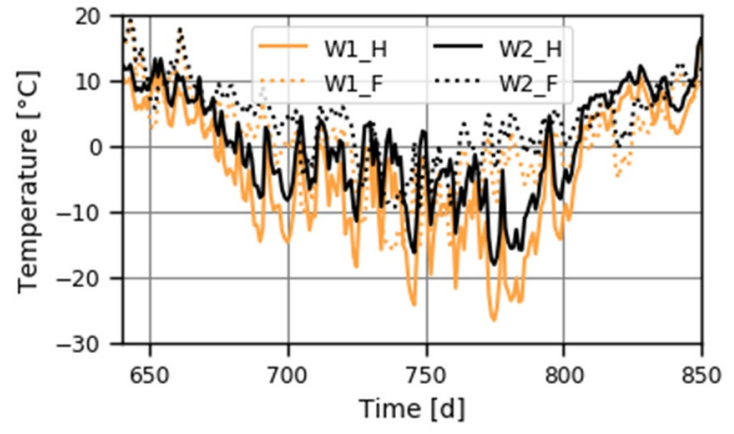

Fig. 6. Temperature profiles at critical position 1 for the case with no air leakage (L0.0) in the city of Winnipeg. Results are shown only for the heating season, from October to April.

\section{Conclusions and future work}

The objective of this work was to assess the potential effects of climate change on the moisture performance of typical Canadian wood-frame walls using hygrothermal simulations. Five cities having different climate characteristics were considered: Vancouver (BC), Ottawa (ON), St. John's (NL), Calgary (AB) and Winnipeg (MB). Two wood-frame walls of a 3.5 -storey $(10 \mathrm{~m})$ residential building having a brick cladding were investigated: a wall with stud cavity insulation and a wall with added exterior insulation. The orientation of the wall was selected as the one with the highest potential of air exfiltration in each city and for each climate data set. Wind-driven rain was calculated for these orientations. Air leakage rate of 0.10 $\mathrm{L} /\left(\mathrm{sm}^{2}\right)$, corresponding to the recommended maximum air leakage rate for building with the warm side relative humidity not greater than $55 \%$, was tested. Moisture content was used as the performance indicator. Two positions in the wall were analyzed: the outer layer of OSB and a small area located at the interior bottom side of OSB. Results obtained for the future timeline (2062-2092) were compared to the baseline period (1986-2016).

Moisture accumulated in the outer layer of OSB showed an increasing trend for the future time period in Ottawa, St. John's and Calgary whereas a decreasing trend is observed in Vancouver and Winnipeg. However, given that the wall orientation used was not the one leading to the highest winddriven rain load, a definitive conclusion cannot yet be made. At the bottom of the interior side of OSB, the results showed that the risk of moisture accumulation due to air leakage will decrease for both types of wall in all cities investigated. This means that the limit of $0.10 \mathrm{~L} /\left(\mathrm{sm}^{2}\right)$ air leakage rate for buildings having warm side relative humidity of less than $55 \%$ may be reconsidered in the future. These findings will be consolidated in a future work, taking into account the uncertainties in climate data.

This work was carried out by the National Research Council of Canada with funding from Infrastructure Canada in support of the Pan Canadian Framework on Clean Growth and Climate Change. The authors are very thankful for their support.

\section{References}

1. P. Mukhopadhyaya, K. Kumaran, M. Nofal, F. Tariku, D. van Reenen, $7^{\text {th }}$ Symposium on Building Physics in the Nordic Countries (2005)

2. T. Ojanen, M. Kumaran, Symp. on Moisture Problems in Building Walls (1995)

3. NBCC, National Building Code of Canada (National Research Council of Canada, 2015)

4. IPCC, Climate change 2014. Synthesis report. Intergovernmental Panel on Climate Change (IPCC, 2014)

5. M. A. Lacasse, H. Ge, M. Hegel, R. Jutras, A. Laouadi, G. Sturgeon, J. Wells, Guideline on Design for Durability of Building Envelopes (NRC, 2018)

6. ASHRAE, ASHRAE Hanbook. Fundamentals (ASHRAE, 2017)

7. A. Gaur, M. Lacasse, M. Armstrong, Data, 4, 72, (2019)

8. S. Cornick, R. Djebbar and W. A. Dalgliesh, Building and Environment, 38, 1367 (2003)

9. M. Kumaran, J. C. Lackey, F. Tariku, D. van Reenen, A thermal and moisture transport property database for common building and insulation materials (NRC, 2002)

10. ISO, ISO 6946 Building components and building elements - Thermal resistance and thermal transmittance - Calculation methods (ISO, 2017)

11. F. P. Incropera and D. P. DeWitt, Fundamentals of heat andmass transfer (John Wiley and Sons., 1996)

12. ANSI/ASHRAE, ASHRAE Standard 160-2016. Criteria for Moisture-Control Design Analysis in Buildings (ASHRAE, 2016)

13. W. Maref, M. Armstrong, M. Rousseau, C. Thivierge, M. Nicholls, G. L. W. Ganapathy, $13^{\text {th }}$ Camadian Conference on Building Science and Technology (2011) 